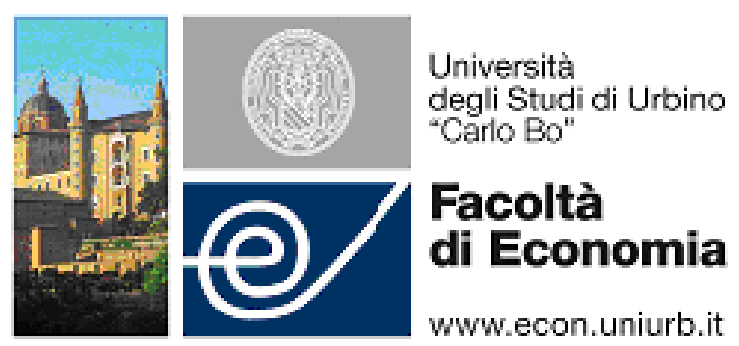

WP-EMS

Working Papers Series in Economics, Mathematics and Statistics

\title{
"THE ROLE OF NETWORK GOVERNANCE MODELS IN THE DESIGN OF LOCAL EHEALTH POLICIES"
}

- Valentina Albano, (U. Roma III) 


\title{
The Role of Network Governance Models in the Design of Local eHealth Policies
}

\author{
Valentina Albano \\ University of Rome III, Faculty of Economics "Federico Caffè", Rome, Italy \\ valentina.albano@uniroma3.it
}

\begin{abstract}
This paper aims at contributing to the rich debate over the obstacles to the diffusion of eHealth technologies by investigating the role of the institutional setting on the success or failure of an IT diffusion policy. This work focuses on the policy network perspective and it is based on the expectation that the internal characteristics of the policy network influence the policy design. The main goal of this paper is to investigate how eHealth policy networks operate and to determine whether a more effective network governance configuration exists that could improve the design and deployment of successful eHealth projects. This work presents a case study of three eHealth policy networks (Region-governed network, eHealth Local Board-governed network, and a Local Health Agencies' Consortium-governed network). The focus of this investigation is on how the three models of network governance operate and influence the design of strategies to face five main eHealth challenges identified by scholars and practitioners: financial challenges; IT challenges; change management challenges; institutional challenges and sharing best practices and evaluation tools.
\end{abstract}

JEL Classification: I180, M150

Key words: IT Management, e-Health, Government Policy, Regulation.

\section{Introduction}

Electronic health (eHealth) refers to the delivery of health care with support from various information and communication technologies, such as electronic health records, telemedicine, clinical decision support systems, and computerized provider order entry (Eysenbach, 2001). The European Commission issued the eHealth Action Plan in 2004 (European Commission, 2004), recognizing the piv- 
otal role of eHealth with respect to the present and future socio-economic and financial challenges faced by national healthcare authorities in Europe. The importance of eHealth has been reiterated in the Digital Agenda for Europe (European Commission, 2010) and in the preliminary consultations on the eHealth Action Plan 2012-2020.

It is widely believed that eHealth can address many of the problems currently faced by health care systems, improving the quality of care, increasing the efficiency of healthcare work, and improving the accessibility of healthcare services and the effectiveness of medical interventions and patient care (Fleurant et al., 2011; Jamal et al., 2009, Stretmann et al. 2006). Nevertheless, despite institutional programs and enthusiastic declarations of the potential of eHealth, its adoption has progressed slowly (Angst, Agarwal, 2009; Bates, 2005; Simon et al. 2007). Moreover, there is significant variability among countries and local healthcare systems in terms of policy aims, priorities and stages of deployment (Era Project, 2007).

This paper aims to contribute to the rich debate on the obstacles to the process of eHealth diffusion (see among others Anderson, 2007; Dixon, 2007 and Angst, Agarwal, 2009)by adopting the approach, not yet adequately explored, of deeply investigating the role of the institutional setting in the success or failure of an IT diffusion policy (Löfgren, 2007). In fact, as Löfgren argues (2007), traditional approaches explain the success or failure of public eService policies through the concept of "IT maturity", which is often based on fairly simple benchmarking based on technological aspects.

Many scholars have converged on the concept of a policy network as a way to understand the dynamics of policy-making on complex issues ((see Marsh, 1998; Rhodes and Marsh, 1990; Daguerre, 2011; Hoeijmakers et al., 2007; Acevedo and Common, 2006). Rhodes (1997) defines the policy network as a cluster of organizations that are connected by resource dependencies, emphasizing the structural relationship between the political institutions. According to this approach, the design choices of policy arrangements are influenced by the internal characteristics of the network, such as the particular network structures linking actors and their concerns.

It is widely believed that the activities required to implement a health IT agenda involve the entire health care system, which is made up of various stakeholders (i.e. public entities, private sector companies, hospital systems and individual physicians) that hold different interests, ideas and values.

Therefore, the main goal of this paper is to investigate how the characteristics of the local healthcare policy network influence the design of the policy arrangements related to the diffusion of eHealth and to determine whether a more effective network governance configuration - in terms of the mechanisms of coordination and control of network-level activities - exists that could improve the design and deployment of successful eHealth projects.

An exploratory case study was undertaken to address these research questions. This study was based on a selection of three Italian healthcare networks that exemplify the different theoretical models of network governance established by 
Provan and Kenis (2007), here renamed Region-governed network, eHealth Local Board-governed network, and Local Health Agencies' Consortium-governed network). This study focused on the Italian context because the decision-making process is disseminated across a wide set of stakeholders that make up the national healthcare system (i.e., Ministry of Health, regional governments, local health agencies, general practitioners, private healthcare providers, etc.), which has led to the development of widely varied patterns of innovation. In fact, the levels of computerization and innovation differ significantly between regions, as do the strategic, organizational and technological choice.

We outlined the essential characteristics of each model of network governance. For each of these models, we analyzed the outcomes achieved at the network level, expressed here in terms of the eHealth political agenda, and assessed their effectiveness. For the purpose of this paper, network effectiveness is defined in terms of the ability to address five main challenges to eHealth implementation identified by scholars and practitioners: financial challenges; IT challenges; change management challenges; institutional challenges and sharing best practices and evaluation tools.

The paper is structured as follows. In Section 2 we discuss the network governance approach by focusing on the eHealth and healthcare literature, while in Section 3 we describe the strategic challenges facing eHealth implementation. The research approach here adopted is described in Section 4, and the case studies are presented in Section 5 and discussed in Section 6. Remarks and conclusion are given in the final section.

\section{"Policy network" and "network governance" in the eHeatlh and Healthcare literature}

The role of the network has not yet been sufficiently explored in the eHealth literature. While many studies argue that eHealth enables communication and both inter-organizational and inter-professional integration (Munkovold and Ellingsen, 2007), the concept of a policy network and its contribution to understanding the dynamics of eHealth policy-making remain unexplored.

Nevertheless, because the stakeholders involved in the eHealth decisionmaking process are the same as those involved in the local healthcare network, useful insights are provided by the literature on healthcare management.

In recent years, the success of the Integrated Care paradigm (Øvretveit, 1998; Kodner and Spreeuwenberg, 2002) has contributed to a shift of the research focus from the individual health care organization - primarily the hospital - (Gittell, 2002; Gittell et al. 2000; Shortell et al. 1994) to the healthcare delivery network (Shortell et al., 1995). This emerging literature on the healthcare network has examined its structures, processes and relational characteristics. 
A first stream in the literature analyzes the network model and its strategic and organizational characteristics, considering nodes as the main units of analysis (Lega, 1998; Larzgoitia and Starfield, 1997). These studies focus on analyzing the benefits that the model provides to organizations, e.g., a more rational use of resources or more learning opportunities.

A second stream prefers to observe the dynamics of coordination rather than the network nodes, aiming to describe the structure and operation of the network (Fennell and Warnecke, 1988; Starkweather, 1990). A great deal of attention has been devoted to the exploration of the impact of the network structure on trust (Meijboom, 2004), the innovation process (Phillips, 2006), and quality (Gill, 2011). Other studies analyze the impact of the network structure on the political healthcare agenda (Lewis, 2005; Hoeijmakers et al, 2007). These studies mainly investigate the interconnections among participants in the policy process and explore their ability to influence policy development, while the relative effectiveness of different network structures has not been addressed. More investigation is required to determine how the network structure should be chosen and what impact the network structure has on the effectiveness of the political agenda.

Provan and Kenis (2007) provide interesting insights to address these issues. The Authors focus on the governance of organizational networks - defined in terms of the mechanisms of coordination and control of network-level activities performed - and its impact on network effectiveness. Network effectiveness is defined as the attainment of positive network-level outcomes that could not be achieved independently by individual organizations. From this perspective, the eHealth policy network can be considered as a set of players working together to obtain the common outcome of the eHealth political agenda.

Provan and Kenis (2007) identify three network forms with specific structural properties and the conditions under which each form is effective.

Lead organization-governed network: a network in which a lead organization takes a central coordinating role, facilitating and enabling collaboration. Power is generally centralized, and communication and decision making may be top-down. A lead organization provides administration to the network and/or facilitates the activities of member organizations in their efforts to achieve network goals. The goals of the member organizations may be closely aligned with the goals of the lead organization. The role of the lead organization may emerge from the members themselves based on what seems to be most efficient and effective; alternatively, it may be mandated.

Participants-governed network: a network in which the members themselves collaborate to achieve goals that would otherwise be outside the reach of individual organizations. The governance of a participant-governed network can be either formal (e.g., based on regular meetings) or informal. Power in the network is symmetrical, at least regarding network-level decisions, despite differences in resource capabilities, organizational size and performance. A participant-governed network is not characterized by the presence of a formal administrative entity, alt- 
hough some administrative and coordination activities may be performed by a subset of the full network.

Network administrative organization (NAO): a network in which a separate administrative entity is established specifically to undertake governance activities. This administrative unit operates as a central node for communication, coordination and decision making. More formalized NAOs typically have board structures that include all or a subset of network members addressing strategic-level network concerns, while the operational decisions are left to the NAO leader.

According to Provan and Kenis (2007), the successful adoption of a specific form of governance is based on four structural contingencies: trust, the number of network participants, consensus on the goals of the network and the need of network-level competencies. These authors argue that as trust becomes less densely distributed throughout the network, as the number of participants increases, as the goal consensus declines and as the need for network-level competencies increases, networks governed by a lead organization or an NAO are likely to become more effective than a participants-governed network (p.237).

Nevertheless, the Authors emphasize that moving from the potential of a model of governance to its success depends on the capabilities of the network managers: specifically, on how managers respond to three basic tensions inherent in network governance:

- Efficiency versus inclusiveness - the need for an inclusive approach is often at odds with the need to be efficient and responsive.

- Internal versus external legitimacy - because a network must be recognized both externally and internally as credible and representative of the members' interests, an effective network governance structure must be responsive to the need for both internal and external legitimacy.

- $\quad$ Flexibility versus stability - a trade-off exists between stability and being flexible enough to quickly address issues.

The stability of a network can contribute to its legitimacy, but it can also lead to rigidity in its governance process, structures, and culture.

\section{eHealth policy challenges}

The strategic importance of eHealth to increase the sustainability of the healthcare system and improve the quality of care, along with the pressures applied by the European Community encouraging the adoption of a cross-borders eHealth framework, have led to studies addressing the issue of eHealth policy making. Many of these studies describe countries' visions and strategies (Mount et al, 2000; Bernstein et al., 2005; Stead et al, 2005; Stroetmann et al. 2011), but most do not move beyond a basic description of the policy ideas and the actors behind them. 
Both policy makers and scholars have discussed the challenges to and critical factors in the success of eHealth strategies (Freidman et al, 2009; Dixon, 2007; Gerber, 2009). These authors argue that the success of eHealth initiatives depends on both the selection of the right technology and the ability to manage a set of challenges and adopt appropriate strategies to overcome them. From this perspective, the effectiveness of the eHealth policy agenda, defined as the network-level outcomes, can be considered in terms of its ability to address these eHealth policy challenges.

Because these challenges are at the network level, a collaborative governance approach is considered essential (Gerber, 2009; Friedman et al., 2009; Stroetmann et al. 2011). The challenges can be clustered into five macro-categories:

1. Financial challenges

2. IT challenges

3. Change management challenges

4. Institutional challenges

5. Sharing best practices and evaluation tools

1. Financial Challenges. Cost is often cited as the primary reason that the health care field has not embraced IT as quickly as other information-intensive industries (Simon et al., 2007; Anderson, 2007; Bates 2005). Moreover, the realization of socio-economic benefits may require a medium to long-term time horizon that discourages further investment (Friedman et al. 2009; Kevin, 2010). Financial realities play an even more significant role when the healthcare system is based mainly on public support. Thus, the identification of new sustainable business models and innovative financial solutions, including public-private partnerships, is a critical factor in the development of eHealth (Dixon, 2007; Stroetmann et al. 2011).

2. IT Challenges. Scholars agree that the development of appropriate data structures and data definitions are critical to the success of an eHealth project, as are the definition of a plan for managing data and information products and quality assurance/compliance programs (Friedman et al. 2009; Gerber, 2009; Gil-Garcìa and Pardo, 2005). Nevertheless, as Gil-Garcìa and Pardo (2005) note, the challenge in this area consists not only of obtaining agreement but also engaging the necessary partners in the development and adoption of common structures and standards. Another critical factor, especially due to the inter-organizational nature of eHealth applications, is the involvement of the healthcare network as a whole in addressing interoperability issues. Interoperability issues include both technical aspects, such as standards-enabling connectivity, and semantic aspects and political/organizational issues (Friedman et al. 2009; Gerber, 2009; Gil-Garcìa and Pardo, 2005).

Moreover, the presence of many competing IT vendors, each with its own product, makes the adoption of certification systems for vendor applications and the imposition of standards important strategic issues (Anderson, 2007). Finally, policy makers must address privacy and security concerns. In fact, 
many scholars and policy makers argue that successfully establishing a network for the exchange of health information depends on the ability to protect personal data and the trust in the system that people will hold as a result (Friedman et al. 2009; Gerber, 2009; Gil-Garcìa and Pardo, 2005; Stroetmann et al. 2011).

3. Change management challenges. The pervasive adoption of technological solutions requires the development of change management interventions to affect the behaviors of individual users and, therefore, the degree of consensus around and involvement in the change (Friedman et al. 2009 Gil-Garcìa and Pardo, 2005; Dixon, 2007, Stroetmann et al. 2011). Change management interventions are particularly critical in the healthcare domain because the field is characterized by strong professional autonomy. Healthcare professionals are also frequently opposed to the influence of the computer culture embedded in Health IT because they do not recognize its legitimacy (Coiera, 1999). Thus, IS development should be oriented toward user participation (Berg, 1999), and training is critical to the success of eHealth projects (Brown, 2000; Gil-Garcia and Pardo, 2005). Training can be instrumental to the development of the specific skills required to use the new system or implement new procedures, and it can also be used as leverage to build consensus and disseminate project results (Dixon, 2007).

4. Institutional and legal challenges. Additional challenges are related to the institutional framework and the policy environment in which governmental organizations operate. Institutions are characterized by their laws and regulations and by the norms, actions, or behaviors that people accept as good or take for granted. In particular, the lack of regulations related to privacy, confidentiality, liability, and data protection led to a slowdown of eHealth deployment in several countries (Friedman et al. 2009; Garcìa and Pardo, 2005; Stroetmann et al. 2011; Anderson, 2007). Moreover, Gil-Garcìa and Pardo (2005) argue that in many countries, government agencies and programs frequently act as independent and autonomous units without taking the actions of other public organizations into account. This can constrain efforts to use technology to integrate or share information across multiple agencies. Finally, scholars and practitioners agree that the length and complexity of eHealth projects requires a steady, long-term commitment by authorities and management (Friedman et al., 2009).

5. Sharing of best practices and evaluation tools. A successful strategy fosters knowledge transfer (Dixon, 2007; Friedman et al, 2009). The use and dissemination of best practices can support decision making. Best practices can represent important information premises that drive policy makers and reduce the risk of investment. Moreover, sharing best practices is an excellent opportunity to encourage the greater rationalization of efforts by promoting the approach of "re-use". It is also important to create global agreement on how to coherently measure the adoption of health IT. Using joint assessment and evaluation tools, it is important to identify both factors in success and the reasons for failure and to record the difficulties experienced by participants (Dixon, 2007). 


\section{Research Approach}

As emphasized above, this paper investigates how the characteristics of the local policy network influence the design of eHealth interventions and studies whether it is possible to identify a model of network governance that leads to more appropriate strategies for addressing eHealth challenges.

An exploratory case study was undertaken to address these research questions. This study was based on a selection of three Italian healthcare networks that exemplify the different theoretical models of network governance established by Provan and Kenis (2007).

We first outlined the essential characteristics of each model of network governance. For each of these models, we analyzed the outcomes achieved at the network level, expressed here in terms of the eHealth political agenda, and assessed their effectiveness. For the purpose of this paper, network effectiveness is defined in terms of the ability to address the 5 categories of eHealth challenges identified in the literature review.

To better explain the different levels of effectiveness obtained by the three models, the findings are discussed in light of the conditions of effectiveness proposed by Provan and Kenis (2007). In this way, it is possible to evaluate their explanatory effectiveness with respect to the analyzed cases and to the issue of the eHealth policy network.

The case study was conducted by analyzing a set of documents, including eHealth and/or eGovernment plans, regulations, resolutions and technical reports. Since we focused on highly formalized institutional policies, the study of the available documentation was useful to reveal the paths taken by the three local healthcare networks with respect to their eHealth deployment.

\section{Case study}

\section{Background}

In Italy, the Constitutional Reform of 2001 introduced a radical change in the relative roles and responsibilities of the State and the Regional governments with respect to healthcare issues. In particular, the reform attributed legislative authority over health protection to the Regional governments. The Ministry of Health determines the essential principles and guarantees the system's fairness by monitoring the Fundamental Levels of Healthcare Services, i.e., the services that are guaranteed by each regional healthcare service as appropriate for specific clinical 
conditions and healthcare settings. In line with this new configuration of roles and responsibilities, eHealth policy is defined in each region by roadmaps developed through cooperative activity between the central and regional authorities.

However, local eHealth policies are influenced by additional factors beyond the interactions between the central and Regional governments. The Regional governments must also interact with a variety of entities with different levels of operational and financial autonomy, which may exert a significant effect on eHealth choices. These entities include the local health agencies responsible for the organization of healthcare services in a geographical sub-area of the region, hospitals, pharmacies, private healthcare providers, and general practitioners. These individuals and entities make up the policy network that makes decisions related to eHealth adoption at the local level.

\section{Three modes of network governance}

The first network mode suggested by Provan and Kenis (2007), the lead organization-governed network, is exemplified by the Lombardy's healthcare network, in which the regional government (Lombardy Region) is the lead organization with the main responsibility for eHealth policy. The Lombardy Region aims to develop an integrated network that includes all the organizations and healthcare professionals working in the area through a centralized and systematic approach.

In this "Region-governed network", the eHealth strategy is carried out along with the development of a region-wide project, the CRS-SISS (Regional Services Card and Socio-Health Information System - Carta Regionale dei Servizi Sistema Informativo Socio-Sanitario), which aims to develop an ICT infrastructure connecting all the healthcare providers in the region. The Regional government has delegated the project development to a publicly owned IT service company (Lombardia Informatica) working as a technical partner, but it has retained responsibility for the "project government" and, therefore, its promotion, financing and direct management. The monitoring and governance of the project was initially assigned to a Technical Committee made up of representatives of the General Directorates involved ("Health" and "Family and Social Solidarity") and of the publicly owned IT service company. Two years after the shift from the pilot phase to the implementation of the project in all the district in the region, a Users Committee was set up that consisted of all the stakeholders of the regional healthcare system.

The main goals of the Users Committee are as follows: to ensure alignment between users and the project team, to verify that the design assumptions fit with actual organizational processes, and to verify the functionality and the technical aspects of integration. These formalized tasks reveal that the involvement of healthcare stakeholders is essentially limited to issues related to the adoption of a project whose essential characteristics have already been defined. Thus, healthcare 
stakeholders are not directly involved in decision making related to the definition of eHealth policy.

However, in 2009, the project governance was redefined, and a strong emphasis was placed on greater user involvement: in particular, on involvement from local health agencies at both the operational and strategic levels. A Strategic Committee composed of members of the Regional government and some general managers of local health agencies has been established with the missions of providing general guidelines, controlling the performance of services and making fundamental decisions.

The Apulian healthcare network exemplifies the second type of network identified by Provan and Kenis (2007), the participant-governed network. This network has been renamed "eHealth Local Board-governed network" since it is governed by a collegial body in which the main participants in the regional healthcare system discuss eHealth strategies (the Apulian Health Board). This Board was established in 2007 through a regional regulation to satisfy the need for a more collaborative structure governing technological innovation processes in healthcare. This need was highlighted in the Apulian Plan for eHealth, which was launched in 2006 by the regional government. In particular, the plan establishes that the Apulian eHealth Board features involvement from the Department for Health, the Regional Agency for Health, local health agencies, public hospitals, University hospitals (IRCCS) and private healthcare providers. The Board also includes Innovapuglia, a publicly owned IT service company, that provides technical and organizational support for the implementation of the electronic health plan.

The primary objective of the Apulian eHealth Board is the realization of an institutional steering committee for the real and continuous government of all eHealth plans, projects and initiatives realized by both the regional government and public or private healthcare providers.

Although in its initial formulation, the Apulian eHealth Board was defined to be representative of all the institutional players in the regional healthcare system, in reality, later regulations limited participation to members of the regional government (the Department for Health and the Regional Agency for Health) and the technical partner.

The other stakeholders, especially the local health agencies, are involved in Technical Working Groups working on specific issues or projects. Since 2007, 19 Technical Working Groups have been established, focusing on both strategic (e.g., the "IT Assessment" Technical Working Group and the "Fundraising" Technical Working Group) and technical issues (e.g., the "IT" Technical Working Group). Most of the Technical Working Groups were established following the launch of the N-SISR project (New Regional Health Information System, Nuovo Sistema Informativo Sanitario Regionale). The N-SISR is the main regional eHealth project aiming to digitize 32 administrative and clinical processes. Technical Working Groups have been recognized as a way to ensure greater compliance between the system requirements and the actual needs of the healthcare professionals. 
Provan and Kenis's third type of network, the Network Administrative Organization (NAO), is exemplified by the Veneto's healthcare network that is governed by a separate administrative entity, established by the local health agencies working in the regional area, called Consortium Arsenàl.it. The Consortium Arsenàl.it constitutes a spontaneous and voluntary aggregation of the 23 local health agencies and hospital trusts of an Italian Region that has established an eHealth consultancy agency to serve its associated members. . In this "LHA Consortiumgoverned network" the Consortium works to develop and coordinate eHealth projects involving the local health agencies, enabling the achievement of innovation objectives that were beyond the reach of the individual agencies. As shareholders, the members collaborate to establish the general guidelines and the governance system through general meetings of the associated members and by appointing members of the board, composed of general managers from all the provinces. The operational decisions are made by the General Manager of the Consortium, supported by the staff. The Veneto Region is not among the members of the Consortium. However, it is a privileged stakeholder because it informs the Consortium of the guidelines it intends to establish, requests opinions and technical investigations and develops special projects aimed at implementing regional policies. Arsènal.it represents all the health agencies in the Region and acts as a fundraising group, giving it a significant influence on the orientation of regional policy.

\section{Findings}

The case study clearly illustrates that the different networks can be effective in coping with eHealth challenges, with each model exhibiting different strengths and weaknesses in interpreting and promoting eHealth choices.

The first interesting differences between the networks are related to their strategic and technological priorities (Table 1).

Table 1. Strategic and technological priorities in the three analyzed networks

\begin{tabular}{|c|c|c|c|}
\hline & $\begin{array}{l}\text { Region-governed } \\
\text { network }\end{array}$ & $\begin{array}{l}\text { LHA Consorti- } \\
\text { um-governed } \\
\text { network }\end{array}$ & $\begin{array}{l}\text { eHealth Local } \\
\text { Board-governed } \\
\text { network }\end{array}$ \\
\hline $\begin{array}{l}\text { Strategic priorities } \\
\text { - Efficiency and } \\
\text { cost reduction }\end{array}$ & High & Moderate & High \\
\hline $\begin{array}{c}\text { Quality im- } \\
\text { provement and } \\
\text { accessibility of }\end{array}$ & Moderate & High & Moderate \\
\hline
\end{tabular}




\begin{tabular}{|c|c|c|c|}
\hline $\begin{array}{c}\text { Technological priorities } \\
\text { Health Clinical } \\
\text { Information Net- } \\
\text { work }\end{array}$ & High & Moderate & High \\
\hline$\bullet \quad$ Telemedicine & Moderate & High & Moderate \\
\hline
\end{tabular}

The objectives that recur in all three networks are efficiency and cost reduction, the streamlining of organizational processes, quality improvements and accessibility of care, and professional growth.

All these objectives can be achieved through the adoption of the so-called Integrated Health Clinical Information Network (EC, 2007) and especially through the development of distributed Electronic Health Record Systems, which is scheduled in all three regional strategies in line with the European and national roadmaps.

However, a more careful observation shows that there are significant differences between the priorities pursued by these models. In particular, both the Region-governed network and the eHealth Local Board-governed network pay greater attention to the objectives of efficiency and the development of IT applications for the digitization of administrative processes and the monitoring of expenditures. The LHA Consortium-governed network appears to be more oriented toward ensuring the quality and accessibility of healthcare services than toward the economic issues. This focus explains the greater attention paid by local health agencies to the development of Telemedicine applications, i.e., personalized health systems and services (e.g., remote patient monitoring, tele-consultation, and tele-care) (EC, 2007). In fact, the Consortium Arsenàl.it was established to observe Telemedicine applications and only later developed competences in the broader domain of eHealth.

The following discussion analyzes the three networks and compares them in terms of how they respond to the five eHealth challenges identified above.

\section{Financial challenges}

While the three networks consider financial aspects to be critical, they adopt significantly different approaches. In the Region-governed network, the regional government directly financed the CRS-SISS project. However, to ensure sustainability, this network has also exploited the potential of public-private partnerships. In particular, the instrument of project financing provides the financial coverage for the project, allowing the Region to pay only when the project is closed and on 
the basis of services effectively received and activated. Neither of the other two networks features a public-private financial partnership.

In the LHA Consortium-governed network model Arsenàl.it approaches financial issues through a strong commitment to fundraising at both the regional and European Community levels. This has enabled the development of internal expertise that ensures the sustainability of the Consortium and enables the launch of new project activities. However, this orientation towards fundraising could have a considerable influence on decision making, favoring specific eHealth projects over others depending on the funding opportunities identified for each. Furthermore, this approach can also present a significant obstacle to developing a long-term vision because projects are often short-lived and fragmented.

The main problem in the eHealth Local Board-governed network is not fundraising but the need to funnel the available grants (mainly EC funding and national funding) into planning that is as systematic, long-term and homogeneous as possible. A first intervention involved the redefinition of the responsibilities for the management of these funds among the different regional units.

\section{IT challenges}

The approach to IT challenges is strongly affected by the overall strategy for eHealth diffusion in the three networks analyzed here. In all three investigated networks, the policy makers are aware of the strategic importance of taking an integrated approach to eHealth to fully exploit its potential. Nevertheless, the specific strategies chosen are very different, and they have been adopted at very different times.

In the Region-governed network, the eHealth strategy has led to the development of a single large regional project that acts as an incubator for all new projects. Indeed, over the years, a number of initiatives and projects have been added to the CRS-SISS project with the aim of supporting the development of semantic standards and ICT architectures to extend and improve quality and data sharing at both the regional and national and European levels. A comprehensive IT infrastructure has been developed that integrates all the healthcare providers' information systems with the regional health network, enabling the access and exchange of patient data across the entire region. The Lombardy Region has adopted an incremental approach to integration based on the identification of relatively small issues at a time, but for the whole region. The initial activities included the development of a robust identification and authorization solution and support for the construction of local Information Systems. After the IT infrastructure was completed in 2006, the priorities shifted from administrative processes, which were now completely digitized, to clinical applications. The Regional government's interest in combining the needs for unity, systematic intervention and con- 
trol with the need to respect the operating independence of healthcare providers led to the adoption of a "non-invasive" approach. This approach views the structure of CRS-SISS as a model of a federated system based on the integration of already existing local systems and that respects the operational procedures in use. To ensure the proper functioning of the overall system, healthcare providers must integrate their local systems with the regional health information network according to the rules and standards defined by the technical partner. The company also supports healthcare providers in selecting between the different products available for integration and the various certified regional vendors.

In contrast, the Apulian eHealth Board was established in a context in which individual healthcare providers had already individually developed many IT applications, but these applications functioned only at the organizational or departmental levels (stovepipe). The eHealth Local Board has attempted to merge previously funded initiatives in a coordinated and systemic intervention called the New Regional Health Information System (N-SISR). Moreover, the board must oversee the Regional governments' development of inter-organizational systems. Finally, it must define the integration requirements with the help of the technical partner, including the requirements for interfacing and interoperability with the regional Information Systems that must be followed by local health agencies when building their internal Information Systems. The eHealth Local Board is also responsible for the validation of projects initiated by individual healthcare organizations.

The Consortium Arsenàl.it adopts a different approach to IT challenges due to the lack of a strong regional intervention, which is associated with the need for the Consortium to meet its members' specific needs and associate its projects with fundraising activities. The Consortium faces the problem of interoperability between many projects launched at different times and often with different logics and purposes. Four projects form the cornerstones of the eHealth strategy of the LHA Consortium; some of these are funded by the European Community, and others are funded by the Region. However, only one of these projects involves all the regional healthcare districts, while the others focus on pilot areas. The team drafted various solutions that were screened by and shared with suppliers and clinicians engaged in different projects with the involvement of qualified experts. A solution was identified that could be implemented over time, and it was chosen on the basis of efficiency, stability and reliability criteria. The cooperative platform and the standards applied in the new projects are in line with those of previously launched projects. Moreover, systems that had already been developed for other regional projects has been re-used in an advanced manner. However, this approach has contributed to a slowdown of the projects implementation and led to a greater effort in terms of the resources spent. Finally, note that the effort of the LHA Consortium is more focused on fostering research on interoperability issues than on defining an effective strategy for integration between different network members. 


\section{Change management issues}

Significant differences exist between the realization strategies of the projects discussed here. One pervasive approach is that of the CRS-SISS project of the Region-governed network, in which all technological and organizational problems are addressed at the regional level.

The same approach was taken in the N-SISR project developed by the eHealth Local Board-governed network. The only region-wide project of the LHA Consortium-governed network is the result of the "re-use" initiative of a previous project that was successfully developed in an individual regional district. Consequently, we can argue that in this case, a focused approach was adopted.

All three networks converge on the same approach to change management. This may be due to the success obtained by IT scholars and practitioners using the participatory-design approach (Berg, 1999). In all three networks, working groups composed of representatives of the IT providers and users were established to develop a constructive dialogue to identify actual user needs and translate them into system functionalities. As the Region-governed network shows, customer orientation is a key element of the success of an IT system and its sustainability. As soon as the Lombardy Region and its technical partner Lombardia Informatica began to engage healthcare professionals in the design, development and implementation of clinical guidelines, the systems' acceptance rate began to increase. Gradually, health professionals have begun to think actively about how to improve their working processes and about the role of ICT in this change.

Training is the second change-management tool used in all three networks. Training is used to ensure user familiarity with the system functionalities and as a powerful instrument to communicate the institutional commitment to eHealth. The LHA Consortium uses e-learning and Web 2.0 tools to disseminate training. Web 2.0 is also exploited by the Consortium to communicate innovations to citizens, representing the third pillar of the change-management activities in the three cases analyzed here. One significant difference distinguishes the Region-governed network from the others. To stimulate and promote the use of the eHealth system, to communicate its benefits to patients and to offset the disadvantages encountered in the early step of the SISS adoption process, in 2003 the Lombardy Region introduced a set of financial incentives for general practitioners. In 2008, similar financial incentives were introduced to promote eBooking functionalities among pharmacists. As soon as the system was completely established, the use of CRS-SISS services was explicitly imposed on all healthcare providers by a regional law.

\section{Institutional and legal issues}

The strong institutional commitment that characterized the Region-governed network has fostered the introduction of a robust legislative and regulatory framework and a long-term vision. In particular, the legislative framework sup- 
porting the development of the CRS-SISS project establishes the clear and explicit inclusion of regional information system in regional planning, a clear definition of roles and responsibilities of all the stakeholders involved, measurable strategic objectives, and agreements with public and private healthcare providers to adhere to the project. Critical issues related to privacy and data processing have also been adequately addressed by legislative action.

A strong political commitment is also present in the eHealth Local Boardgoverned network. Since the launch of the Apulian eHealth Plan in 2006, many provisions have been produced to formalize the activities of the Apulian eHealth Board, to regulate the development of regional information systems and particularly of N-SISR, and to address critical issues, such as privacy and data protection.

In contrast, the absence of the regional government among the members of Arsenàl.it appears to lead to the absence of its direct involvement in institutional and legal issues. Furthermore, the historical prominence of local health agencies in regional eHealth policy appears to contribute to this Veneto's lower normative production in eHealth issues than in the other two Regions analyzed in this study. However, the research activities carried out by the Consortium and the recently launched projects suggest that it may also exert a significant influence on these issues in the future.

Finally, the issue of inter-institutional relationships is explicitly addressed in the Region-governed network. The regional government has progressively imposed the integration of private healthcare providers and welfare institutions and providers into the regional healthcare information system. In the eHealth Local Board-governed network, the inter-institutional integration has been planned but not realized, while this issue is not explicitly addressed by the LHA's Consortium.

\section{Best practices and evaluation tools}

The strong pressure exerted at the institutional level - in particular, by the European Community - concerning the identification and promotion of best practices has fostered a strong emphasis on their value and assessment in all three networks. The logic of best practices and "re-use" has especially taken root in the LHA Consortium-governed network, due to its role as the integrator of the projects and activities of the local healthcare agencies; to a lesser degree, best practices and "reuse" have come to play a role in the eHealth Local Board-governed network. These issues are less relevant in the Region-governed network, where a centralized and systematic approach to eHealth development prevails. Regarding the IT evaluation issues, the LHA Consortium has explicitly included these issues among its strategic priorities through the launch of a specific project on the subject funded by the European Community. The evaluation of IT projects is one of the activities attributed to the eHealth Local Board, while in the Region-governed network this task has been delegated to the technical partner. In both cases, attention is focused 
primarily on ensuring the consistency of the projects developed by network members with regional eHealth projects.

Table 2. eHealth challenges addressed by the three governance networks

\begin{tabular}{|c|c|c|c|}
\hline $\begin{array}{c}\text { eHealth chal- } \\
\text { lenges categorie(s) }\end{array}$ & $\begin{array}{c}\text { Region-governed net- } \\
\text { work }\end{array}$ & $\begin{array}{l}\text { LHA Consorti- } \\
\text { um-governed } \\
\text { network }\end{array}$ & $\begin{array}{l}\text { eHealth Local } \\
\text { Board-governed } \\
\text { network }\end{array}$ \\
\hline $\begin{array}{l}\text { 1. Financial } \\
\qquad \begin{array}{l}\text { Find ade- } \\
\text { quate fund- } \\
\text { ing }\end{array}\end{array}$ & $\begin{array}{c}\text { Highly } \\
\text { Regional funding and ex- } \\
\text { ploitation of a Public- } \\
\text { Private Partnership }\end{array}$ & $\begin{array}{l}\text { Highly } \\
\text { Strong fundraising } \\
\text { activity }\end{array}$ & $\begin{array}{l}\text { Moderately } \\
\text { Passive approach: } \\
\text { management of re- } \\
\text { ceived EC funding }\end{array}$ \\
\hline $\begin{array}{l}\text { 2. IT } \\
\begin{array}{l}\text { - Infor- } \\
\text { mation and } \\
\text { data quality }\end{array}\end{array}$ & $\begin{array}{l}\text { Highly } \\
\text { Project development dele- } \\
\text { gated to a technical partner }\end{array}$ & $\begin{array}{l}\text { Highly } \\
\text { The Consortium de- } \\
\text { velops and coordi- } \\
\text { nates projects }\end{array}$ & $\begin{array}{c}\text { Highly } \\
\text { Project development } \\
\text { delegated to a tech- } \\
\text { nical partner }\end{array}$ \\
\hline $\begin{array}{l}\text { - Interoper- } \\
\text { ability } \\
\text { (technical, } \\
\text { semantic } \\
\text { and organi- } \\
\text { zational as- } \\
\text { pects) }\end{array}$ & $\begin{array}{c}\text { Highly } \\
\text { Top-down development of a } \\
\text { single regional project }\end{array}$ & $\begin{array}{c}\text { Poorly } \\
\text { Need to face in- } \\
\text { teroperability prob- } \\
\text { lems among different } \\
\text { projects. Research } \\
\text { on interoperability } \\
\text { issues vs. deploy- } \\
\text { ment of integration } \\
\text { strategies. }\end{array}$ & $\begin{array}{c}\text { Moderately } \\
\text { Previously funded in- } \\
\text { itiatives merged in a } \\
\text { broader intervention } \\
\text { (N-SISR) }\end{array}$ \\
\hline $\begin{array}{l}\text { - } \quad \text { Standardi- } \\
\text { zation }\end{array}$ & $\begin{array}{l}\text { Highly } \\
\text { Standards for the integra- } \\
\text { tion of local systems with } \\
\text { the regional health infor- } \\
\text { mation network; vendor } \\
\text { certifications }\end{array}$ & $\begin{array}{c}\text { Poorly } \\
\text { Research on stand- } \\
\text { ardization issues vs. } \\
\text { deployment of } \\
\text { standardization } \\
\text { strategies }\end{array}$ & $\begin{array}{l}\text { Moderately } \\
\text { Board responsible } \\
\text { for the validation of } \\
\text { local projects }\end{array}$ \\
\hline $\begin{array}{l}\text { - Security } \\
\text { (identifica- } \\
\text { tion \& au- } \\
\text { thorization } \\
\text { systems) }\end{array}$ & $\begin{array}{c}\text { Highly } \\
\text { Developed }\end{array}$ & $\begin{array}{l}\text { Moderately } \\
\text { Issue addressed in } \\
\text { each project }\end{array}$ & $\begin{array}{c}\text { Highly } \\
\text { Under development }\end{array}$ \\
\hline
\end{tabular}




\begin{tabular}{|c|c|c|c|}
\hline $\begin{array}{l}\text { 3. Change manage- } \\
\text { ment } \\
\text { - Resistance } \\
\text { to change }\end{array}$ & $\begin{array}{l}\text { Highly } \\
\text { Pervasive approach; user } \\
\text { involvement in IT develop- } \\
\text { ment; training \& communi- } \\
\text { cation; economic incentives }\end{array}$ & $\begin{array}{l}\text { Moderately } \\
\text { Focused approach; } \\
\text { user involvement in } \\
\text { IT development; } \\
\text { training, \& commu- } \\
\text { nication }\end{array}$ & $\begin{array}{l}\text { Moderately } \\
\text { Pervasive approach; } \\
\text { user involvement in } \\
\text { IT development; } \\
\text { training \& communi- } \\
\text { cation }\end{array}$ \\
\hline $\begin{array}{l}\text { 4. Institutional and } \\
\text { legal } \\
\text { - Institution- } \\
\text { al commit- } \\
\text { ment }\end{array}$ & $\begin{array}{l}\text { High } \\
\text { Regional government leads } \\
\text { the eHealth policy network }\end{array}$ & $\begin{array}{l}\text { Low } \\
\text { Regional govern- } \\
\text { ment is not a mem- } \\
\text { ber of the Consorti- } \\
\text { um }\end{array}$ & $\begin{array}{l}\text { Moderate } \\
\text { Formalization of the } \\
\text { Board functions, } \\
\text { clear regional } \\
\text { eHealth plan }\end{array}$ \\
\hline $\begin{array}{c}\text { - } \quad \text { Need for } \\
\text { Regulations }\end{array}$ & $\begin{array}{l}\text { Highly } \\
\text { Robust legislative and } \\
\text { regulatory framework es- } \\
\text { tablishing strategic objec- } \\
\text { tives, roles, privacy issues } \\
\text { \& data protection... }\end{array}$ & $\begin{array}{l}\text { Poorly } \\
\text { eHealth regulations } \\
\text { are less developed }\end{array}$ & $\begin{array}{l}\text { Highly } \\
\text { Robust regulation of } \\
\text { privacy issues \& da- } \\
\text { ta protection }\end{array}$ \\
\hline $\begin{array}{l}-\quad \text { Inter- } \\
\text { institutional } \\
\text { relationship }\end{array}$ & $\begin{array}{c}\text { Highly } \\
\text { Progressive integration in } \\
\text { the regional IS of private } \\
\text { HC providers and welfare } \\
\text { institutions }\end{array}$ & $\begin{array}{l}\text { Poorly } \\
\text { Issue not explicitly } \\
\text { addressed }\end{array}$ & $\begin{array}{l}\text { Moderately } \\
\text { Inter-institutional in- } \\
\text { tegration planned } \\
\text { but not realized }\end{array}$ \\
\hline $\begin{array}{l}\text { 5. Best practices and } \\
\text { evaluation tools } \\
\text { Knowledge } \\
\text { transfer }\end{array}$ & $\begin{array}{c}\text { Poorly } \\
\text { Regional project as an in- } \\
\text { cubator of all other projects }\end{array}$ & $\begin{array}{l}\text { Highly } \\
\text { Adoption of a "re- } \\
\text { use" approach }\end{array}$ & $\begin{array}{l}\text { Moderately } \\
\text { Previous projects } \\
\text { merged in the N- } \\
\text { SISR }\end{array}$ \\
\hline $\begin{array}{l}\text { Evaluation } \\
\text { tools }\end{array}$ & $\begin{array}{c}\text { Moderately } \\
\text { IT partners assess the local } \\
\text { IT projects and certify IT } \\
\text { vendors }\end{array}$ & $\begin{array}{l}\text { Highly } \\
\text { Launch of a project } \\
\text { on the topic }\end{array}$ & $\begin{array}{l}\text { Moderately } \\
\text { The Board evaluates } \\
\text { the local IT projects }\end{array}$ \\
\hline
\end{tabular}




\section{Discussion}

This analysis of the three eHealth policy networks demonstrates that the three different modes of network governance produced substantially different decisions affecting the degree of technological innovation in healthcare processes and the degree of innovation diffusion across a territorial area.

In particular, the Region-governed network is notable for its adoption of a systematic approach and the speed with which all the regional healthcare services have been digitized. In the eHealth Local Board-governed network the Board has also provided a significant stimulus for the development of complex initiatives at the regional level over a short time (e.g. the N-SISR project).

All three networks are composed of large numbers of actors competing for the acquisition of the same limited resources and with conflicting objectives. At first glance, a reduction of the decision-making group or the identification of a lead organization could simplify the decision-making process, leading at least to more immediate solutions.

The LHA Consortium-governed network exhibits a higher level of trust among its members than the other two networks. This is the only network that was not imposed at the institutional level but was spontaneously developed by organizations that share a common goal. This fact, along with its relatively small number of members (limited to the 23 local health agencies), suggest that this network may be the best suited for achieving effective network-level outcomes. In addition, the Consortium's strong commitment to the development of specific eHealth competencies and sharing those competencies with its members is highly valuable when tasks that must be developed at the network level require significant interdependence among members along with task-specific competencies. However, the case study results show that the Consortium does not address all the strategic issues and that this network is less effective in extending its approach to eHealth at the regional level.

To better understand the differences among the three models and the apparently lower efficiency of the LHA Consortium-governed network with respect to the dimensions analyzed here, we focus on how the three models respond to three basic tensions inherent in network governance: efficiency versus inclusiveness, internal versus external legitimacy, and flexibility versus stability.

\section{Efficiency versus inclusiveness}

The case study shows that in the LHA Consortium-governed network, strategic decisions are made at the Associated General Meeting, a body that is representative of all the consortium members. Its operations are managed by a staff that has developed expertise in technological issues and fundraising. This tension between efficiency and inclusiveness is also taken into account and managed in the other two networks analyzed here. The eHealth Local Board-governed network was initially more oriented toward inclusiveness, but it has quickly adopted an approach 
aimed to reduce the burden of direct involvement in the decision-making process. While the Apulian eHealth Board was originally established to include all the stakeholders of the regional healthcare system, the set of norms detailing its organizational structure only include members representing the regional government and the technical partner. The involvement of the network as a whole is, therefore, limited only to the phases of system development and IT adoption. This choice appears to be essentially oriented to the creation of consensus with respect to IT applications in an effort to increase the likelihood of actual use.

In the Region-governed networks, efficiency has traditionally prevailed over inclusiveness. In 2009, the direct involvement of these networks' members in eHealth decision-making widened through the establishment of the Strategic Committee composed of a selection of General Managers of local health agencies and representatives of the regional government. This approach, in contrast with the "normal" network evolution (according to Provan and Kenis (2007), the evolution of a brokered form to shared governance is quite unlikely) could be due to the increasing complexity of the regional eHealth project and to the cultural influence of the emerging participatory governance approach on the Regional government.

\section{Internal versus external legitimacy}

The LHA Consortium-governed network tends to balance the two forms of legitimacy. As the central network administrator, the Consortium Arsenàlit can represent the network externally, while the need for interaction between members, which is instrumental to the development of internal legitimacy, can be addressed through the representative structure, i.e., the Associated General Meeting. The other two networks have also developed mechanisms that balance their needs for internal and external legitimacy. In the case of the eHealth Local Board-governed network, internal legitimacy is clearly ensured by a strong participatory focus, but external legitimacy also appears to be established by the institutionalization of the network at the regional level. In the case of Region-governed networks, the use of working groups aiming to involve all members of the network creates an opportunity for internal legitimacy that complements the strong legitimacy reflected by the Regional government onto the network.

\section{Flexibility versus stability}

The case study demonstrates that the Region-governed network is particularly stable and that the eHealth Local Board-governed network is stable because it was created by the Regional government. In contrast, the LHA Consortium relies on fundraising and might, therefore, be considered the least stable. Nevertheless, it is characterized by its members' strong commitment, and it receives legitimacy from the institutional system. Moreover, the LHA Consortium has established mechanisms for managing different activities and short-term-oriented tasks, demonstrating its great flexibility. 
In conclusion, the analysis performed here shows that the networks' governance structures influence strategic decisions related to eHealth diffusion, along with the ways in which some internal tensions are managed. However, other factors require further investigation, such as the composition of each network and the role of each player in decision making.

To understand the relationships between the governance arrangements of the policy networks and eHealth policy choices more deeply, it appears insufficient to focus narrowly on the degree of centralization of decision making and, hence, on the level of participation of network members. Instead, it is important to investigate the characteristics of the players involved in the decision-making process and how their values and goals may influence the choices being made and the success of eHealth strategies.

The three networks analyzed here are characterized by their different models of network governance, but they also involve different participants. In particular, both the Region-governed network and the eHealth Local Board-governed network feature a strong commitment from the regional government, albeit with different levels of involvement. In contrast, the LHA Consortium consists only of local health agencies. The diversity in the choice of strategic priorities, which is oriented more toward interventions in clinical processes in the case of the Consortium and toward interventions in administrative processes in the other two cases, could be due to the prevalence of different goals and values in the different networks. The Consortium represents the goals and values of the professional group, while the other two networks represent the goals and values of institutional management. Moreover, this study emphasizes that while the LHA Consortium excels in the development of new knowledge and technical innovations, it suffers from a lack of commitment at the institutional level, primarily from the Regional government, which plays a key role in healthcare IT development strategies in the other two cases.

\section{Conclusions}

This paper investigates how different eHealth local policy networks operate and the effect of different modes of network governance on the political arrangements related to eHealth diffusion. Using a case study, three local health policy networks (Region-governed network, Local eHealth Board-governed network and LHA Consortium-governed network) that exemplify the three types of governance network provided by Provan and Kenis (2007) have been analyzed. Moreover the levels of efficacy of each model have been compared, focusing on their ability to address main eHealth challenges defined by scholars and policy makers.

The study found that in the complex issue of eHealth adoption, which features a wide and heterogeneous policy network, the model of the Region-governed network, characterized by a strong institutional commitment, appears to ensure rapid 
and systemic eHealth adoption. Its success is also due to the capability of the Regional government to effectively manage the tensions described by Provan and Kenis (2007) that develop inside the network: efficiency versus inclusiveness, internal versus external legitimacy, and flexibility versus stability.

Moreover, the results highlight the need to investigate other factors besides the mechanisms of network coordination and control, such as the network composition and each player's role in the decision-making process, to more deeply understand the relationship between the governance structure of the policy network in which the eHealth policies are defined and the success of these policies.

At a theoretical level, this paper contributes to the debate over the obstacles to the process of eHealth diffusion, emphasizing that this is influenced by both technological maturity and the dynamics developing within the network of actors involved in decision making about eHealth strategies.

Understanding these dynamics also has important practical implications, as it provides insights for healthcare policymakers about how to define a system of governance suitable to speed up the process of innovation in the healthcare system.

\section{References}

Acevedo, B., Common, R. (2006). Governance and the Management of Networks in the Public Sector. Public Management Review, 8(3):395-414

Anderson, J.G. (2007). Social, ethical and legal barriers to E-health, International Journal of Medical Informatics Volume 76(5):480-483

Bates, D.W. (2005). Physicians and Ambulatory Electronic Health Records, Health Affairs, 24(5):1180-1189.

Berg, M. (1999). Patient care information systems and health care work: a sociotecnical approach. International Journal of Medical Informatics, 55(2):87-101.

Bernstein, K., Bruun-Rasmussen, M., Vingtoft, S., Andersen, S., Nøhr, C. (2005). Modelling and implementing electronic health records in Denmark, International Journal of Medical Informatics 74 (2): 213-220

Coiera, E. (1999). The impact of culture on technology... how do we create a clinical culture of innovation, Medical Journal of Australia, 171:508-509.

Dixon B.E. (2007). A Roadmap for the Adoption of e-Health, e-Service Journal, 5(3)

Ellingsen G., Munkovold G. (2007). Infrastructural arrangements for integrated care: implementing an electronic nursing plan in a psychogeriatric ward. International Journal of Integrated Care 7.

ERA Project (2007). eHealth priorities and strategies in European countries, available at http://www.ehealth-era.org/publications/publications.htm

European Commission (2004). eHealth - making healthcare better for European citizens: An action plan for a European eHealth Area. Brussels.

European Commission (2010). 245 final. A Digital Agenda for Europe, Brussels. Meijboom, Bert (2004) Networks for integrated care provision: an economic approach based on opportunism and trust. Health policy, 69(1): 33

Eysenbach, G. (2001) What is e-health? Journal of Medical Internet Research, 3(2): E20. 
Fennell, M.L., Warnecke, R.B. (1988). Diffusion of Medical Innovations: An Applied Network Analysis, Plenum, New York.

Fleurant, M., Kell, R., Love, J., Jenter, C., Volk, L.A, Zhang, F, Bates, D, Simon, S.R. (2011) Massachusetts E-Health Project Increased Physicians' Ability To Use Registries, And Signals Progress Toward Better Care. Health Affairs,30(7):1256-1264

Friedman, C.P. Iakovidis, I., Debenedetti, L., Lorenzi, N.M. (2009). Across the Atlantic cooperation to address international challenges in eHealth and health IT: Managing toward a common goal. International Journal of Medical Informatics, 78:778-784.

Gerber T. (2009). Health Information Technology: Dispatches from the revolution. Health Affairs, 28(2):390-391

Gil-Garcia, J.R., Pardo, T.A. (2005). E-government success factors: Mapping practical tools to theoretical foundations. Government Information Quarterly, 22:187-216

Gill, L. (2011). Qualitative Triadic Study of the Relational Factors Influencing the Formation of Quality in a Community-Based Aged Health Care Service Network. Health marketing quarterly, 28(2): 155

Gittell, J.H. (2002). Relationships between service providers and their impact on customers. Journal of Service Research, 4(4):299-311.

Gittell, J.H., Fairfield K., Bierbaum B., Head W., Jackson R., Kelly, M., Laskin, R., Lipson, S., Siliski, J., Thornhill, T., Zuckerman, J. (2000). Impact of relational coordination on the quality of care, post-operative pain and functioning, and the length of stay: a nine-hospital study of surgical patients. Medical Care, 38(8):807-819

Hoeijmakers, M., De Leeuw, E., Kenis, P., De Vries, N.K. (2007). Local health policy development processes in the Netherlands: an expanded toolbox for health promotion. Health Promotion International, 22(2): 112-121.

Jamal, A, McKenzie, K, Clark, M. (2009). The impact of health information technology on the quality of medical and health care: a systematic review. Health Information Management Journal 38:26-3

Kevin, C.W. (2010). Accelerating Innovation In Information and Communication Technology for Health, Health Affairs, 29(2): 2789-283

Kodner, D.I., Spreeuwengerg, C.. (2002). Integrated care: meaning, logic, applications, and implications - a discussion paper. International Journal of Integrated Care $14 ; 2$.

Larzigoitia, I., Starfield, B. (1997). Reform of primary health care: the case of Spain. Health Policy, 41:121-137

Lega, F. (1998). Scelte strategiche e definizione dei confini dell'ospedale. Dalla struttura focalizzata alla struttura a rete, Organizzazione Sanitaria, 1: 43-66

Lewis, J. M. (2005). Health Policy and Politics: networks, ideas and power. IP Communications, Melbourne.

Löfgren, K. (2007). The Governance of eGovernment: A governance perspective on the Swedish eGovernment strategy. Public Policy and Administration 22:335

Marsh, D.: The development of the policy network approach, in D. Marsh (ed.), Comparing Policy Networks, Buckingham: Open University Press (1998)

Mount, C.D., Kelman, C.W., Smith, L.R., Douglas, R.M. (2000). An integrated electronic health record and information system for Australia? Medical Journal of Australia 172: 25-27.

Ovretveit, J. (1998). Integrated care: models and issues. Goteborg, Sweden: A nordic school of Public Health Briefing paper.

Phillips, W. (2006) Investigating innovation in complex health care supply networks: an initial conceptual framework. Health services management research, 19(3): 197

Provan, K., \& Kenis, P. (2007). Modes of network governance: Structure, management, and effectiveness. Journal of Public Administration Research and Theory, 18(2), 229-252.

Rhodes, R.A.W. (1997). Understanding Governance: Policy Networks, Governance, Reflexivity and Accountability, Buckingham: Open University Press.

Rhodes, R.A.W. Marsh, D. (1990). Policy networks: a British perspective, Journal of Theoretical Politics 2(3): 293-317. 
Shortel, S., Gillies R., Anderson D. (1994). The new world of Managed Care: Creating Organized Delivery Systems. Health Affairs 13:46-64

Shortell, S., Gillies, R., Devers, K. (1995). Reinventing the American hospital. The Milbank Quarterly, 73(2):131-60.

Simon, S.R., Kaushal, R., Cleary, P.D., Jenter, C.A., Volk, L.A., Poon, E.G., (2007). Correlates of Electronic Health Record Adoption in Office Practices: A Statewide Survey Journal of the American Medical Informatics Association, 14(1): 110-117.

Starkweather, D.B. (1990). Competition, Integration, and Diversification: Seven Hospitals of Growthville, U.S.A., Journal of Health Administration Education, 8(4):519-570.

Stead, W.W., Kelly, B.J., Kolodner, R.M. (2005). Achievable steps toward building a national health information infrastructure in the United States, Journal of the American Medical Informatics Association 12(2): 113-120.

Stroetmann, K. A., Artmann, J., Stroetmann, V. (2011) Developing national eHealth infrastructures - results and lessons from Europe. AMIA Annual Symposium Proceeding, 2011:13471354 